Cite as: Nguyen, N. M., Killen, C., Kock, A., \& Gemünden, H. G. (2018). The Use of Effectuation in Projects: The Influence of Business Case Control, Portfolio Monitoring Intensity and Project Innovativeness. International Journal of Project Management. Volume 36, no. 8, pp 1054-1067.

\title{
The Use of Effectuation in Projects: The Influence of Business Case Control, Portfolio Monitoring Intensity and Project Innovativeness
}

\author{
Na Mi Nguyen \\ Technische Universität Berlin, Chair for Technology and Innovation Management \\ Catherine P Killen \\ University of Technology Sydney, School of the Built Environment, \\ Alexander Kock* \\ Technische Universität Darmstadt, Chair for Technology and Innovation Management \\ Hans Georg Gemünden \\ Handelshoyskolen BI, Department of Leadership \& Organization
}

\begin{abstract}
Project management approaches are evolving to be more flexible and adaptive to meet the challenges associated with an increasingly complex and dynamic environment. However, potential changes in the underpinning logic supporting project decision making have scarcely been considered. We investigate the role of effectuation, a decision logic most commonly associated with entrepreneurship, as an alternative decision-making approach to the rational 'causation' logic that has traditionally underpinned project management processes. We develop and test a model to explore the portfolio- and project-level influences on the application of effectuation in project management. We find that portfolio governance mechanisms related to business case use and portfolio monitoring inhibit the use of effectuation, while project innovativeness is associated with increased use of effectuation. The paper contributes to research and practice by empirically investigating the antecedents to the use of effectuation decision-making logic in project and portfolio management through a multi-level model.
\end{abstract}




\section{The Use of Effectuation in Projects: The Influence of Business Case Control, Portfolio Monitoring Intensity and Project Innovativeness}

\section{Introduction}

Project management approaches have largely been based on a rational decision logic that stems from its origins in meeting the demands of managing complex, technical projects (Söderlund, 2011; Turner et al., 2013). However, project environments are changing, with project management practices now applied to a wide range of projects in an increasing number of industries (Jensen et al., 2016). This shift in the project landscape is accompanied by an increasing focus on the strategic contribution of the project portfolio, and the need for enhanced levels of innovation, responsiveness and flexibility (Kock and Gemünden, 2016; Kopmann et al., 2017). Much has been done to meet the challenges created by such demands within project and portfolio frameworks (Martinsuo, 2013); however, the reliance on the traditional 'rational' or 'causal' logic may limit the effectiveness of project decision making in such environments (Huff, 2016). Effectuation is a form of decision-making logic that has been shown to be used for entrepreneurial decision making (Sarasvathy, 2001). In this paper, we explore the role of effectuation as an alternative decision-making logic in project environments.

Decision making is a key task in project management (Stingl and Geraldi, 2017) and project portfolio management (PPM) (Kock and Gemünden, 2016; Meifort 2016). Decisions must be made about priorities, approaches, time, and resources in order to develop or sustain competitive advantage and enhance business success (Cooper et al., 2002). Traditional project management methods and tools such as business plans, forecasts, financial methods, and frequent monitoring and analysis (Salomo et al., 2007) are designed for a 'causal' decision making mindset. However, as organizations across industry sectors are faced with 
increasingly complex and dynamic environments, project management approaches are evolving to meet the changing needs. The emergence of an alternative decision-making logic, effectuation, may play a part in this shift in project management approaches (Huff, 2016).

Effectuation decision-making logic is characterized by using available resources rather than pre-defined goals to shape projects, considering the level of loss that is 'affordable', emphasizing partnerships and networks over competitive analyses, and exploiting contingencies through flexibility and adaptability (Sarasvathy, 2001). In contrast, causationthe logic considered to underpin traditional rational planning approaches_-begins with predefined project targets and goals, builds predictive models and then seeks to obtain the required means and to control the outcome.

First identified as a decision-making logic in entrepreneurial environments, the concept of effectuation has generated interest in a range of management fields, such as marketing (Read et al., 2009), finance (Wiltbank et al., 2009), and R\&D (Blauth et al., 2014; Brettel et al., 2012). Although effectual decision making has not been studied in a PPM context, our review of the literature suggests that effectuation may provide an alternative decision-making logic to better deal with uncertainty in project-based environments. We answer the call to conduct a multi-level research study on effectuation theory (Perry et al., 2012) in our investigation of the role of effectuation in project and portfolio management. Our study measures the extent to which effectuation practices are used in projects and explores the influence of project type and portfolio governance approaches on the use of effectuation. Our multi-level model considers the innovativeness of the project as a task variable on the project level, and the use of business cases and traditional portfolio monitoring as governance principles on the project portfolio level as potential determinants of effectual decision making. The study is underpinned by the following research questions: How does the innovativeness of a project influence the use of effectual decision making? How do business case application and 
monitoring on the portfolio level influence the use of effectual decision making on the project level?

We empirically address these questions using multi-level data from 420 projects nested in the project portfolios of 108 medium to large companies. Our study contributes to research and practice in several ways. We highlight the implications for decision making from the shift away from traditional project planning tools toward a more flexible and adaptive approach and introduce effectuation as an alternative decision logic that plays a role in project contexts. We develop and test a research model to explore how portfolio- and project-level determinants influence the application of effectual decision making. Furthermore, this study is one of the first multi-level studies in the project portfolio literature (Meifort, 2016).

\section{Theoretical background}

\subsection{The shift in project and PPM decision making}

In traditional project planning, project success implies reaching a predefined goal in terms of time, cost, and quality (Atkinson, 1999). Project management methods are strongly linked to goals and prediction and a variety of project management tools and techniques exist to manage these goals (Besner and Hobbs, 2013). These tools include business plans or forecasting to calculate and minimize risks, frequent monitoring and analysis, the calculation of expected returns, and evaluation of multiple alternatives to select to the best possible strategy (Turner et al., 2013).

The increasing number of projects, the extended scope of project activities and their growing strategic importance has led to the need to manage multiple projects and to the increasing use of PPM approaches. PPM focuses on how projects are aligned with strategic goals of various stakeholder groups, resources, and interdependencies between projects. 
Typically, the projects of a portfolio are prioritized, selected, integrated, managed, and controlled considering the impacts on other projects and the expected performance impacts. Empirical research has repeatedly shown that these activities have a significantly positive effect on project portfolio success (e.g., Cooper et al.; 2002; Killen et al., 2008; Teller et al., 2012; Jonas et al., 2013; Kock et al., 2016). PPM is an important organizational capability that can provide competitive advantages to organizations (Killen et al. 2012).

Decisions in both project and portfolio management environments have traditionally been assumed to adopt a rational or 'causation-based' decision logic. However traditional project planning paradigms are increasingly being overturned as projects are now often embedded in fast-moving market sectors (Cooke-Davies et al., 2007), and linked with a more complex working environment (Maylor et al., 2008). Organizational and project complexity is a result of increasing risks, turbulence and uncertainties (Martinsuo, 2013) determined by the uniqueness of the project, the amount of information to be processed, the technical scope, or the interdependency between technology, people, and organizations (Engwall, 2003).

The literature emphasizes the challenge of managing projects in times of increasing complexity and change (Maylor et al., 2008) and the need for relevant supporting capabilities. This challenge is amplified for innovative projects where adaptation and evolution must be embraced to avoid stifling innovation (Salomo et al., 2007). Contingency theory proposes that management approaches will be most effective when designed to cater for the particular environment (Donaldson, 2001). This is regularly demonstrated in project management research where findings highlight that projects differ, and that project management methods provide best results when tailored to the context (Shenhar, 2001; Hanisch and Wald, 2012). Innovation, particularly the challenge of managing different levels of innovativeness, is a strong theme among literature that emphasizes the benefits of contingency frameworks (Shenhar, 2001; Shenhar and Dvir, 1996). Such contingency approaches advocate designing 
or choosing project management processes to best support aspects such as project type and size, degree of risk, industry, culture and level of innovativeness (Howell et al., 2010). Consequently, project management approaches are evolving to be more adaptable, behavioral (Jaafari, 2003), flexible (Olsson, 2006), improvisational (Jerbrant and Gustavsson, 2013; Leybourne, 2009), and agile (Conforto et al., 2014; Lechler and Yang 2017; Recker et al., 2017). These changes indicate a shift in the ways that decisions need to be made in project environments.

Similarly, the literature reveals that PPM perspectives evolve to meet changing needs in project environments. Repeated research findings reveal a tension between the level of formality and the degree of flexibility (Atkinson, 2006; Salomo et al., 2007; Kock et al., 2015), and highlight the importance of tailoring the PPM approach to suit the context (Martinsuo, 2013; Kopmann et al., 2015). While formality in PPM has been shown to relate to better performance overall (Killen et al., 2008; Teller et al., 2012), too much formality is associated with negative results - especially in innovative environments (Loch, 2000; Salomo et al., 2007; Kock and Gemünden, 2016).

The increasing attention to innovation across society, especially as a driver of competitive advantage, places special emphasis on developing better ways to manage innovation for successful outcomes. Project portfolio concepts emphasize the need for most organizations to maintain a balance of incremental and radical innovation (Cooper et al., 2002). While incremental innovation is more common and is generally a less risky endeavor than radical innovation, the rewards are also more modest. It is the radical innovations that enable organizations to achieve sustainable advantages and higher margins (Kock et al., 2011). Management methods to support each type of innovation differ - in fact one of the major organizational conundrums is how organizations can best 'exploit' existing capabilities through incremental innovation while also 'exploring' new areas and capabilities through 
radical innovation (March, 1991). This challenge has generated a range of studies on organizational ambidexterity, the ability for organizations to successfully manage both incremental and radical innovation (O’Reilly and Tushman, 2013).

PPM plays a strong role in managing innovation - both in recognizing the degree of innovation in projects and tailoring the project management approach, and in applying portfolio level approaches to manage and balance and enable innovation (Killen and Hunt 2010). In addition, by enabling organizational response to change and reconfiguring projects and resources for best portfolio benefit, PPM can act as a dynamic capability and enhance competitive advantage (Killen et al., 2012; Kock and Gemünden, 2016). To remain relevant in the ways it works with the underlying project capabilities and resources, the PPM approach must evolve in response to the changing environment (Winter, 2003),

While the need for appropriate management approaches that are tailored to context is well documented, whether there is a corresponding need for different types of underlying decision logic is less well explored. Supporters of project management approaches such as 'agile' methodologies emphasize the need for a cultural shift in order to effectively transition from traditional methods (Conforto et al., 2014). The rational assumptions and basis for traditional project management tools are also being challenged from other perspectives - for example through 'rethinking' project management research (Cicmil et al., 2006; Svejvig and Andersen, 2015) and other studies (Clegg et al, 2018, Blomquist et al., 2010). A 'rational' mindset and decision making using causation logic is thought to underpin traditional project and portfolio management approaches, however such causative logic draws upon assumptions that may not be valid in times of adaptation and change. Effectuation logic, shown to support a different type of decision making in entrepreneurial and other management contexts, may have relevance in project and portfolio decision environments. Effectuation logic may be especially suited for approaches that are evolving to meet the challenge of change and innovation; 
however the use of effectuation has scarcely been explored in a corporate setting (Brettel et al., 2012; Johansson and McKelvie, 2012) and not at all in a project portfolio environment.

\subsection{Effectuation as a decision-making approach}

Effectuation goes beyond being a flavor of the rational 'causative' approaches to decision making in the face of uncertainty: it draws upon an entirely different logic for decision making. Through a qualitative study of entrepreneurship, Sarasvathy (2001) identified the use of effectuation as a decision logic that provided a flexible and opportunistic process for building new ventures in an uncertain environment. Effectuation is characterised as a dynamic, iterative process of decision making that starts with a set of resources (referred to as 'means') and focuses on selecting between possible goals or outcomes ('effects') that can be created with that set of means (Sarasvathy, 2001). This is in marked contrast to the 'causative' decision logic commonly assumed to be at play in project environments; causation is a decision logic that builds on prediction and processes that "take a particular effect as given and focus on selecting between means to create that effect" (Sarasvathy, 2001, p. 245).

Traditional planning approaches generally draw upon causation and are applied in domains where predictive rationality and given goals are thought to be primary factors that influence outcomes. Causation consists of principles, criteria, and techniques for achieving, generating, and selecting between possible means to accomplish a pre-defined goal. In that way, a clear vision of a desired future is defined as well as a detailed plan of how to achieve it. Following causation logic, the individual makes rational choices based on all relevant information and the estimated utility for each option (Viale, 1992).

Neither effectuation nor causation are thought to be appropriate for all environments. Sarasvathy (2001) claims that causal thinking is more effective in more static environments where the future is possible to predict, while effectuation processes are regarded as more effective when the future is unpredictable. Furthermore, Chandler et al. (2011) argue that 
causation can be understood as a deliberate strategy, which is used, for example, in the preparation of a business plan, whereas effectuation complies with the theory of emergent strategy, for example by building on alternatives based on experiments and flexibility in the context of potential affordable loss (Kopmann et al., 2017). Table 1 highlights the differences between effectuation and causation by summarizing their underlying characteristics.

Table 1: Characteristics of causation and effectuation (Sarasvathy, 2001)

\begin{tabular}{|c|c|c|}
\hline & Causation & Effectuation \\
\hline What is given & Effects and goals are given & $\begin{array}{l}\text { Some means, tools, and resources are } \\
\text { given }\end{array}$ \\
\hline $\begin{array}{l}\text { Decision-making } \\
\text { selection criteria }\end{array}$ & $\begin{array}{l}\text { - Choice between means to achieve } \\
\text { the given effect } \\
\text { - Selection criteria based on expected } \\
\text { return } \\
\text { - Effect-dependent: choice of means if } \\
\text { driven by characteristics of the effect } \\
\text { the decision maker wants to create and } \\
\text { his or her knowledge of possible } \\
\text { means }\end{array}$ & $\begin{array}{l}\text { - Choice between possible effects that } \\
\text { can be created with given means } \\
\text { - Selection criteria based on } \\
\text { affordable loss or acceptable risk } \\
\text { - Actor-dependent: given specific } \\
\text { means, choice of effect is driven by } \\
\text { characteristics of the actor and his or } \\
\text { her ability to discover and use } \\
\text { contingencies }\end{array}$ \\
\hline $\begin{array}{l}\text { Competencies } \\
\text { employed }\end{array}$ & Excellent at exploiting knowledge & Excellent at exploiting contingencies \\
\hline $\begin{array}{l}\text { Context of } \\
\text { relevance }\end{array}$ & More useful in static environments & More useful in dynamic environments \\
\hline $\begin{array}{l}\text { Nature of } \\
\text { unknowns }\end{array}$ & $\begin{array}{l}\text { Focus on the predictable aspects of an } \\
\text { uncertain future }\end{array}$ & $\begin{array}{l}\text { Focus on the controllable aspects of } \\
\text { an unpredictable future }\end{array}$ \\
\hline Underlying logic & $\begin{array}{l}\text { To the extent we can predict future, } \\
\text { we can control it }\end{array}$ & $\begin{array}{l}\text { To the extent we can control future, } \\
\text { we do not need to predict it }\end{array}$ \\
\hline
\end{tabular}

Several studies have examined effectuation in an entrepreneurial context, especially in early development phases and new venture creations (Cai et al., 2016; Johansson and McKelvie, 2012; Read et al., 2009; Reymen et al., 2015). However, effectuation is not limited to the field of entrepreneurship and "can probably be applied much more broadly" (Wiltbank and Sarasvathy, 2010, p. 20). For example, Brettel et al. (2012) showed that corporate employees make use of effectual decision making in order to deal with high levels of uncertainty in R\&D. Although effectuation has not been studied in a PPM context, the literature suggests that effectual decision-making logic may be an appropriate approach to 
meet the needs of the more turbulent environment and deal with decision making under uncertainty. In an analysis of entrepreneurs who manage a portfolio of ventures, Morrish (2009) found effectual decision making in the early stages of venture and portfolio development and an increasing tendency for causation logic as ventures and portfolios mature.

Effectuation logic can be seen as a composite of four cognitive process and behaviors, identified by Sarasvathy as: (1) driven by available means rather than pre-defined goals; (2) affordable loss rather than expected returns; (3) adaptability and acknowledgement of the unexpected rather than exploitation of preexisting knowledge, and (4) partnerships rather than competitive analyses (Chandler et al., 2011; Sarasvathy, 2001). We will follow with a deeper explanation of each of these principles and then provide examples and illustrations from project and portfolio decision environments.

\subsection{Effectuation principles in project management and PPM}

Driven by available means rather than pre-defined goals. The core idea of the meansdriven approach is the focus on available resources and experimenting to create business opportunities for an unpredictable future, rather than the formulation of concrete goals and targets aimed at forecasting the future. Available means could take the form of financial support, or slack resources such as skills or equipment that are not currently in use. Following a means-driven approach allows the decision-maker to explore alternatives, without the constraints of an expected outcome, and to then evaluate multiple options and test different approaches through experimentation.

Making use of effectual reasoning and building on available means in the project context can enable the decision maker to draw upon their identity, skills and networks while considering the inventory of available means to create an outcome. This is at odds with causal 
reasoning that begins with a pre-defined target and promotes planning steps in accordance with the requirements of the project. Project goals based on an effectual approach can be blurry and abstract, especially when contrasted to the detailed project targets developed in traditional causation processes which in turn guide the collection of necessary resources and means.

As project environments are changing, approaches to project management and PPM may also need to change. The increasing push for innovation often takes the form of exploratory projects, where goals are not set, and new options can be explored (Lenfle, 2016). In such environments, available means may influence the evolving project goals. Therefore, in contrast to the main stream of the project portfolio literature, which considers bottleneck resources when prioritizing projects, an effectuation approach recognizes the influence of slack resources, which are not fully committed to existing projects.

Affordable loss rather than expected returns. This principle considers the potential risks of project investments and bases decisions on how much loss is acceptable, while focusing on experimenting with as many strategies as possible with the available means. Affordable loss promotes the creation of more options in the future rather than the maximization of short-term returns. The affordable loss principle considers the available resources as well as the risks involved in using them. Decisions are made considering the level of possible loss with the aim to ensure that any loss will not exceed a level that is 'affordable', i.e. does not lead to unacceptable levels of negative consequences (Berends et al., 2014; Blauth et al., 2014).

In the project management context, the traditional causal decision-logic starts with project planning and uses methods such as business plans or forecasting in order to calculate and minimize risks, as well as calculating expected returns (Salomo et al., 2007). However, in highly innovative projects with a high level of uncertainty, forecasts of financial returns are hard to predict. The application of the principle of affordable loss in project management 
could increase the focus on evaluating potential risks or downsides of investing in a project and de-emphasize financial calculations of expected returns. This may provide benefits especially in highly innovative project environments.

From a portfolio perspective, project decisions are made on the basis of balance between risk and return with the aim of achieving a balanced portfolio. In their framework for project portfolio selection, Archer and Ghasemzadeh (1999) propose that the benefit of each project is measured in term of each project's individual contribution to one or more portfolio objectives, for example economic return, achievement of benefits, market results, and the level of risk. Some degree of risk (measured as a combination of the probability of an event and the consequences associated with that event) is present in all projects on some level. Applying effectual logic from a portfolio perspective would decrease the emphasis on estimates of financial return from the portfolio, and acknowledge that risk is unavoidable, especially in innovation projects and dynamic environments. Limiting risk to fit within the 'affordable loss' gives permission for risk-taking - indeed it sets an expectation of a level of risk across the portfolio of projects. This may enable some projects to be selected despite high risks, as long as portfolio risk remains at an acceptable level.

Adaptability. This principle refers to the degree to which the unexpected is acknowledged and the ways that opportunities are pursued. Effectuation focuses on controllable aspects of an unpredictable future and the underlying logic is: To the extent that we can control the future, we do not need to predict it. Consequently, contingencies and surprises are not seen as risks under the adaptability principle, but rather a source of opportunities. In contrast, causation logic focuses on predictable aspects of an uncertain future. The underlying logic of causation is: To the extent that we can predict the future, we can control it. Contingencies and surprises are avoided or overcome to reach the given project targets. 
Causal logic can be appropriate for decision making in projects with a low level of uncertainty, as flexibility is not required (Brettel et al., 2012). However, random and unplanned events can occur at any time in project environments, such as changes in markets, technologies and the availability of resources. By acknowledging the unexpected and remaining flexible and adaptive to changes in the environment, effectuation principles can provide advantages for decision making. The support for flexibility could enable projects to be managed iteratively to respond to emerging circumstances (Chandler, 2011). Project and Portfolio goals could be changed and shaped over time, making use of contingencies as they arise (Sarasvathy, 2008). The increased focus on agility and responsiveness suggests that this type of decision logic may be applicable in project and portfolio environments (Killen et al., 2012; Krebs, 2008).

Partnerships rather than competitive analyses. This final principle of effectuation takes an external perspective. In order to avoid uncertainty, causation models focus on competitive and market analyses, while effectuation emphasizes on forming partnerships, building strategic alliances and obtaining pre-commitments from self-selected stakeholders as a way to reduce uncertainty.

Partnerships play an important role in many project environments. "An effectual approach risks only resources that can be affordably lost; thus it also drives partnerships as the central method to expand resources" (Sarasvathy et al., 2014, p. 74). Effectual logic focuses on early cooperation with stakeholders and customers in order to extend means and resources, reduce or divide uncertainty and receive support for decision making. Partnerships enable higher levels of control for the future; each partner brings in new means and opportunities that can combine to sculpt the future project. In addition, stakeholders may be able to provide information to reduce ambiguity and uncertainty. For example, in product development projects, pre-commitments from potential customers allow organizations to test their products 
early in the development phases, receive important information on the usage and consequently reduce uncertainty. A longitudinal research study of twelve radical new product development projects revealed that "due to the critical contribution of alliance partners in radical innovation, project managers devoted significant time and effort to finding partners for the purpose of accessing competency based resources, and negotiated appropriate relationships" (McDermott and O'Connor, 2002, p. 431).

\section{Hypotheses}

In this section, we develop hypotheses on the relationships between project and portfolio factors and the use of effectuation logic. We have introduced effectuation as a type of decision logic that may be useful in project and portfolio processes, especially as these processes shift to cater for more dynamic and uncertain environments. To develop our hypotheses, we first explore the innovativeness of the project as a contextual influence for effectual decision making. Innovative projects entail a high degree of uncertainty and predictions might therefore be more difficult to make.

Second, we consider the PPM perspective. An important consideration here is project governance, which "comprises the value system, responsibilities, processes and policies that allow projects to achieve organizational objectives and foster implementation that is in the best interests of all the stakeholders, internal and external, and the corporation itself" (Müller, 2009, p. 4). Thus, project governance provides the structure through which the objectives of the project are set, and the means of attaining those objectives and monitoring performance are determined. Our study focuses on two portfolio governance mechanisms and their relationship with effectual decision making: the use of business cases and the degree of portfolio monitoring. A business case is created to justify a project and is instrumental in supporting strategic decision making at the portfolio level (Kopmann et al., 2015). Portfolio 
monitoring considers the ongoing control of all projects and is therefore also core to portfolio decision making.

Our hypotheses link these three potential influences on decision making with three of the principles of effectuation: 'means-driven approach', 'affordable loss', and 'adaptability'. The fourth principle of effectuation, 'forming partnerships', stands apart from the others in its external perspective and is not included in our hypothesis development. Our decision to focus on the other three principles was influenced by results from the work of Brettel et al. (2012) that found low correlations between the use of the 'forming partnerships' principle and the three other principles ('affordable loss', 'means-driven approach', and 'adaptability') and suggests that these three principles may form a cluster of practices that are commonly used together. In addition, our exploratory study has been designed to include a range of projects, including many that do not have external customers or partners, and therefore would not be able to provide a solid sample on the external 'forming partnerships' aspect of effectuation. The conceptual model is presented in Figure 1.

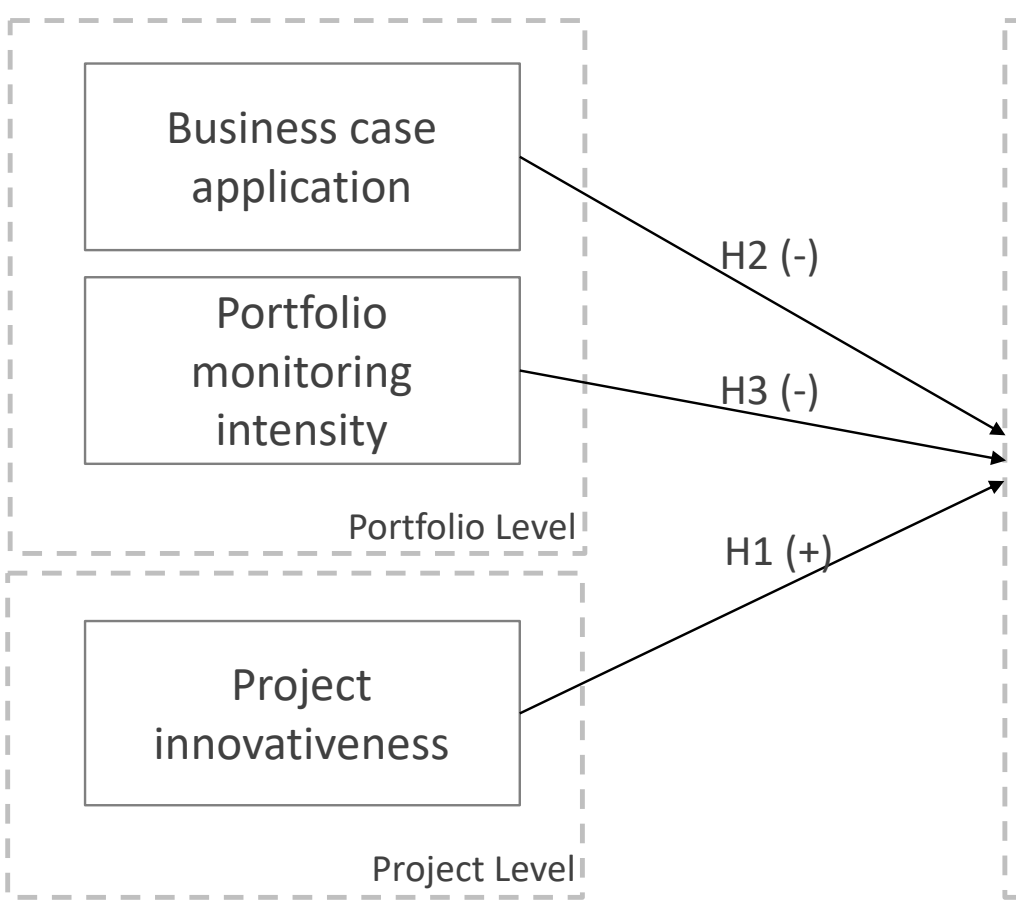

\section{Effectuation}
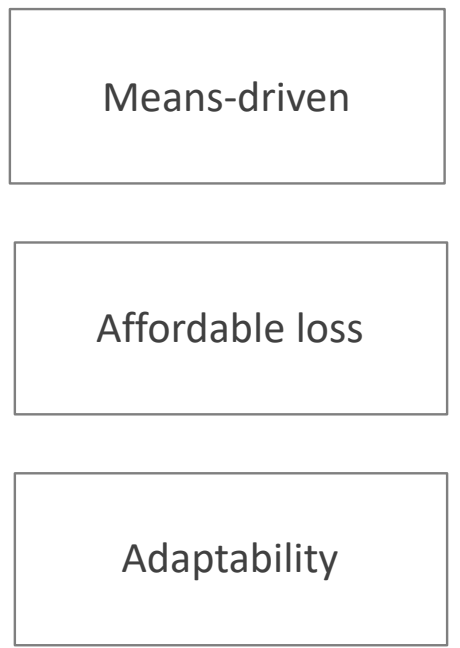

Project Level

Figure 1. Research Framework 


\subsection{Innovativeness of the project}

Innovation in products and services is a major driver for increased profitability, competitive advantage, and shareholder value; therefore, the ability to innovate is vital for organizations (Kock, 2007). Contingency theory can be used to explain research findings that repeatedly show that innovative projects require lower levels of process formality and formal control than projects that are more routine (Conforto and Amaral, 2010; Salomo et al., 2007).

As organizations ramp up their focus on innovation, projects increasingly entail a high level of uncertainty, both through market uncertainty and technological uncertainty (Brettel et al., 2012). Market uncertainty refers to new market requirements and new customer groups. In order to deal with uncertainty, large firms often conduct upfront market research to elicit customer preferences and predict future sales (Read et al., 2009). However, such forecasts are often difficult to make especially for highly innovative projects, suggesting that more flexible and adaptive approaches are required to enable the recognition and pursuit of opportunities. When dealing with multiple innovative projects, the risks are even higher. This suggests that the effectuation logic aspect of 'affordable loss rather than expected returns' could be an appropriate decision-making logic for PPM in times of uncertainty.

Flexibility refers to the ability to adapt to changing situations and environments. Companies that cannot react flexibly will not be able to innovate in the long-term. In the past, best practice studies supported the use of formal product innovation processes with wellplanned activities (Cooper and Kleinschmidt, 1995). These processes have often employed a causal approach where a portfolio of ideas is developed to target pre-defined goals, resources are allocated according to expected discounted cash flow and payback periods. However, further research has identified important differences between managing incremental and radical innovation (Salomo et al., 2007; Kock et al., 2011). Compared to incremental innovation, managing radical innovations is much more challenging as markets, products, and 
customer requirements can all be unfamiliar. Due to the nature of radical innovation, the literature suggests different management approaches for radical innovation (Gemünden et al., 2018; Kamoche and Cunha, 2001). Traditional project management approaches based on planning and control are largely unworkable in innovative environments with high levels of uncertainty and evolution (McDermott and O'Connor, 2002). If decision making employs a causal approach, with a low risk propensity and demand for fast and visible returns, innovative project proposals may not receive support due to high pressure and limited resources.

A balance between structure and flexibility seems to be an appropriate way to manage contradicting demands of control and innovation when acting in highly competitive environments (Kock et al., 2015). Creativity, autonomy, and idea encouragement are also important for innovation (Hennessey and Amabile, 2009). Creative skills can be described as the sum of approaches to risk propensity, tolerance for frustration, attitude to deal with uncertainty, and the need for independence (Blauth et al., 2014). Findings indicate that a corporate culture which allows new ideas to be turned into new innovative projects increases employees' creativity and innovation (Ekvall, 2008; Kock et al., 2015). Past research in new product development has shown that effectual logic positively impacts practiced creativity, while causal decision-making logic has a negative influence (Blauth et al., 2014). Clearly defined goals may be counterproductive for creativity by putting pressure on employees in early project phases (Hennessey and Amabile, 2009). Research in R\&D environments shows how employees use effectual decision logic to deal with high levels of uncertainty (Brettel et al., 2012). Applying effectuation logic, a project manager who has a degree of freedom and an innovative mindset can experiment with available means (resources, knowledge, and network), be creative and adapt to contingencies along the project. Huff (2016) proposes that the use of effectual thinking can increase the capacity to organically create sustainable 
outcomes in the long-term. Based on the demonstrated alignment between effectuation and innovative approaches, we propose:

H1. A high degree of innovativeness of a project is positively related to the use of (a) the means-driven approach, $(b)$ the affordable loss principle, and (c) the adaptability principle.

\subsection{Application of business cases}

Literature highlights the importance of PPM in evaluating, prioritizing, and selecting projects in line with strategy (Kopmann et al., 2017). A common perspective is that projects reflect an organization's business strategy (Artto et al., 2008), thus business cases are recognized as an important function to support strategic planning in project environments (Kopmann et al., 2015).

From a portfolio perspective, business cases demonstrate the advantages of organizational investment in a project and how the project aims to create value, therefore providing a basis for decision making and offering stakeholders transparency regarding the projects. An important aspect of business case control is "the application of business cases within the portfolio structuring and resource allocation phases, where it encompasses not only the presence of a business case, but also its quality in terms of accuracy, validity, comprehensiveness, and comparability" (Kopmann et al., 2015, p. 532). A project's success is not only determined by meeting cost, time, and scope (Serrador and Turner, 2015) but by its delivered business value. A value-focused outcome orientation can give project managers more freedom to innovate if they can provide evidence that more business value will be created. Portfolio-level business case control mechanisms have been shown to be positively related to project portfolio success (Kopmann et al., 2015). 
By establishing business cases organizations aim to avoid contingencies and plan ahead. This can lead to the inability to recognize external and also internal changes. The project managers may feel secure by following the planned procedure and acting to meet the established arrangements. They may not be willing to focus on available means and invest time on change requests and the delivery of arguments and evidence for adjusting the plans. However, it could be that such opportunities do exist within business planning, and that project managers could include slack resources in their business plans and thus follow a means-driven approach. The project manager's actions will depend upon the culture and the business-planning approach: Are project managers expected to follow the plans, or are they primarily expected to contribute to more value creation? In the latter case there is more room for effectual behavior.

However, giving project managers more degrees of freedom to change their plans requires a higher level of coordination between projects. It could result in a higher level of uncertainty and risk for other projects, which compete for the same resources, or those that provide input or rely on the outcomes of other projects. Finally, a more flexible approach to business control could result in the expectation of flexibility from all projects - even if they do not need it. If firms require elaborate business cases for their project proposals, project selection will be limited, and will exclude many projects that could fit well with the affordable loss principle and/or a means-driven approach. The likelihood of finding projects employing such effectuation approaches is lower in these firms. Thus, we suggest that the application of business cases will reduce the use of effectuation approaches.

H2. Business case application is negatively related to the use of (a) the means-driven approach, $(b)$ the affordable loss principle, and (c) the adaptability principle. 


\subsection{Portfolio monitoring intensity}

An important objective of PPM is to monitor the project landscape at the portfolio level evaluating the goals and objectives as well as performance toward those goals and objectives. Monitoring projects for their contribution to strategy can be regarded as a method of control (Lacerda et al., 2011). Monitoring activities can take place from project initiation until closure in order to continuously validate the progress of projects and the overall portfolio in response to changing internal and external conditions. It is important to review whether the project is performing in accordance with plans, budget, and scope or if corrective actions need to be taken while it is still possible to act as most companies discover deviations and changing conditions too late (Gardiner and Stewart, 2000). Frequent portfolio monitoring allows management to react more quickly and make decisions to take corrective actions when undesired discrepancies between project plans and execution occur (Kock and Gemünden 2016). Contingency is also evident in portfolio monitoring approaches; in a study on the relationship between organizational control techniques and portfolio performance, Müller et al. (2008) observed that different control mechanisms are associated with different performance measures.

Monitoring projects from a portfolio level includes oversight of individual projects as well as the examination and control of strategic alignment and targets across the portfolio. While focusing on specific project management requirements related to time, budget and scope, project managers may experience limited autonomy to create and pursue other opportunities. A high intensity of monitoring could reinforce this tendency and steer firms to adopt largely causal decision making and reduce the project manager's freedom to consider a range of options for balancing the level of investment and affordable loss. Thus, in situations of high monitoring intensity, we propose that a project manager would be less likely to experiment with available means to achieve the desired goals or pursue further opportunities. In addition, 
the pressure to fulfill expected returns and satisfy specific criteria would limit adaptability. Therefore, we propose:

H2. Monitoring intensity is negatively related to the use of (a) the means-driven approach, (b) the affordable loss principle, and (c) the adaptability principle.

\section{Method}

\subsection{Sample and data}

The proposed framework requires a two-level model because some constructs are on the level of the project (i.e., effectuation approach and the innovativeness of the project) and others are on the level of the organization/portfolio. We therefore collected multi-level data on 420 projects from 108 companies in order to test our hypotheses. This study is part of a larger survey on the management of project portfolios. The object of analysis is the single project nested in the project portfolio of the respective company. For each firm or business unit, we surveyed two types of informants: a coordinator and several project managers. The coordinator was the immediate manager of the project portfolio and had a good overview of the project landscape and the applied methods, processes and tools. Typical job titles for coordinators were portfolio manager, head of project management office, division manager, or department manager. Project manager informants were responsible for managing a specific project within the project portfolio. This multiple informant approach allowed the integration of information from different perspectives and hierarchies.

The following approach was adopted: first, we contacted portfolio coordinators in mediumsized and large organizations from various industries, providing general information on the study, offering them to register their interest and calling for participation. Forty-six percent of the contacted companies responded to our request with interest. Registered informants received an e-mail with questionnaires and explanations regarding the multi-informant design, 
terms and definitions. Coordinators were asked to distribute the project manager questionnaires to at least three project managers of their respective portfolio. Project managers were instructed to report on their most recently completed project. After the invitations and mailings, we made follow-up phone calls to ensure a high response rate. Overall, we received 145 coordinator questionnaires (44\%) and 442 project manager questionnaires. Since we did not receive both types of questionnaires from every firm and there were some missing values, the final sample included 108 portfolios (33\%) and corresponding 420 projects ( 1 to 17 per firm, average 4, median 3).

All organizations were active in project management and conducted multiple projects simultaneously. The sample includes organizations from diverse industries: $24 \%$ finance, $20 \%$ electronics and IT, 19\% machine building and automotive, $12 \%$ pharmaceuticals and chemicals, $9 \%$ transport and logistics, $8 \%$ utilities, and $8 \%$ others. Portfolio budget was: less than 20 million $€$ in $35 \%$ of the portfolios; between 20 and 100 million $€$ in $41 \%$; and higher than 100 million $€$ in $24 \%$. The median number of projects in each portfolio is 45 .

\subsection{Measurement}

We used multi-item measurement scales with items drawn from the literature on PPM and related fields. We relied on existing scales when possible or adapted scales from previous work to meet our research goals. Informants were asked to rate each item on a seven-point Likert scale from 1 "strongly disagree" to 7 "strongly agree". All item wordings for each construct are shown in the Appendix.

Dependent variables. In line with the hypotheses, the dependent variables in this study reflect three dimensions of effectuation: means-driven, affordable loss, and adaptability. Although empirical measurement of effectuation is still scarce, there are a few pioneering studies that created and validated scales (Brettel et al., 2012; Perry et al., 2012). Following the 
development of scales in an R\&D environment, the operationalization of Brettel et al. (2012) was used and adapted. For each dimension, several items were created in the form of opposing statements, resulting in ten bi-polar items overall. Each effectuation statement was opposed by a corresponding causation statement and project managers were asked to indicate which statement better applied to their project situation on a 7-point scale,

Independent variables. Business case application was measured by the coordinator on the portfolio level using three items capturing the extent to which business cases are used for evaluating and prioritizing project proposals. The items were conceptually developed by Kopmann et al., (2015). Portfolio monitoring control was measured by the coordinator on the portfolio level. The three items were taken from Kock and Gemünden (2016) and measure the frequency and diligence of portfolio monitoring. Innovativeness of the project comprises six items capturing market as well as technological newness of the project. This variable was operationalized based on items from Salomo et al. (2007). The project managers provided data for this construct.

Control variables. We controlled for several variables on the portfolio- and project-level that might affect effectual decision making. On the level of the portfolio, we first controlled for portfolio budget measured as the natural logarithm of the annual overall budget for the project portfolio in million Euros. Second, we controlled for portfolio management formalization, defined as "the extent to which the portfolio management process was clearly defined and specified" (Kock and Gemünden, 2016, p.679). We measured formalization using four items taken from previous literature (Teller et al., 2014). Third, we controlled for the degree to which resource slack exists in the portfolio. We used a single item ("We deliberately hold back resources to have a buffer for unplanned initiatives") to measure portfolio slack. All portfolio-level controls were assessed by the coordinator informant. On the level of the project, we controlled for the size of the project by including project duration 
(natural logarithm of the project length in months) and project budget (natural logarithm of the project budget in thousand Euros). Both variables were assessed by the project manager.

\subsection{Measurement validation}

Item scales were validated by using principal components factor analysis (PCFA) and confirmatory factor analysis (CFA). We ran one analysis for variables on the firm-level (coordinator informant) and one analysis for variables on the individual level (project manager). In both PCAs the items loaded highly on their respective factors and cross-loadings were below 0.30. The CFA on the individual level had an excellent fit (Chi-square (df 96) = 157.16; SRMR $=0.044$; CFI $=0.97$ ), and the CFA on the firm level had a very good fit (chisquare $(\mathrm{df} 32)=60.84 ; \mathrm{SRMR}=0.061 ; \mathrm{CFI}=0.97)$. Overall, the measurement can be considered acceptable.

\subsection{Analysis}

Since the projects are hierarchically nested in their respective portfolios, the multi-level nature of the data must be considered in the analysis. In addition, we aimed to simultaneously examine effects from variables on the first level (projects) and on the second level (portfolio). Therefore we used random effects general least squares (GLS) regression with the portfolio as a grouping variable to test the proposed hypotheses.

\section{RESULTS}

Our findings provide evidence that the three effectuation principles are practiced within our sample, although causation logic is still dominant. The practices 'means-driven', 'affordable loss', and 'adaptability' have mean values of $2.3,3.7$, and 3.5 on a 7-point scale.

The results of the hypotheses tests are documented in Table 2. The innovativeness of the project was positively related to the usage of the effectuation practices 'affordable loss' and 
'adaptability', thus confirming hypotheses H1b and H1c. Our findings show that these two principles of effectuation were used more often when projects showed high innovativeness, however the usage of the effectuation practice 'means-driven' was not significantly related to the innovativeness of the project, and therefore hypothesis 1a could not be supported.

Table 2. Regression results.

\begin{tabular}{|c|c|c|c|}
\hline & $\begin{array}{c}\text { (1) } \\
\text { Means-driven }\end{array}$ & $\begin{array}{c}(2) \\
\text { Affordable loss }\end{array}$ & $\begin{array}{c}\text { (3) } \\
\text { Adaptability }\end{array}$ \\
\hline \multicolumn{4}{|l|}{ Portfolio-level controls } \\
\hline \multirow[t]{2}{*}{ Portfolio budget (ln) } & 0.047 & 0.055 & -0.049 \\
\hline & {$[0.043]$} & [0.037] & {$[0.056]$} \\
\hline \multirow[t]{2}{*}{ Portfolio management formalization } & -0.047 & $0.179 *$ & 0.007 \\
\hline & [0.045] & {$[0.051]$} & [0.061] \\
\hline \multirow[t]{2}{*}{ Portfolio slack } & 0.035 & -0.031 & -0.022 \\
\hline & {$[0.050]$} & [0.074] & {$[0.068]$} \\
\hline \multicolumn{4}{|l|}{ Project-level controls } \\
\hline \multirow[t]{2}{*}{ Project duration $(\ln )$} & -0.048 & 0.033 & 0.154 \\
\hline & [0.101] & [0.109] & [0.103] \\
\hline \multirow[t]{2}{*}{ Project budget (ln) } & -0.034 & $-0.038 \dagger$ & -0.042 \\
\hline & [0.036] & {$[0.020]$} & {$[0.028]$} \\
\hline \multicolumn{4}{|l|}{ Independent variables } \\
\hline \multirow[t]{2}{*}{ Project innovativeness } & -0.051 & $0.172 *$ & $0.258^{*}$ \\
\hline & [0.049] & [0.046] & {$[0.049]$} \\
\hline \multirow[t]{2}{*}{ Business case application } & -0.043 & $-0.100^{*}$ & $-0.087 \dagger$ \\
\hline & [0.039] & [0.041] & {$[0.046]$} \\
\hline \multirow[t]{2}{*}{ Portfolio monitoring intensity } & 0.034 & $-0.092 \dagger$ & $-0.149^{*}$ \\
\hline & [0.054] & {$[0.055]$} & [0.065] \\
\hline \multirow[t]{2}{*}{ Constant } & $2.968^{*}$ & $2.918^{*}$ & $3.496^{*}$ \\
\hline & [0.419] & [0.519] & {$[0.457]$} \\
\hline R-Square (within) & 0.01 & 0.04 & 0.08 \\
\hline R-Square (between) & 0.04 & 0.17 & 0.19 \\
\hline R-Square (overall) & 0.02 & 0.09 & 0.11 \\
\hline Wald Chi-Square & 10.03 & 50.87 & 51.10 \\
\hline
\end{tabular}

Random-Effects GLS regression; robust standard errors in brackets; $\mathrm{n}=420 ; 108$ firms; unstandardized regression coefficients are reported; $\dagger \mathrm{p}<0.10 ; * \mathrm{p}<0.05$. 
Business case logic was negatively related to affordable loss logic and had a marginally significantly negative relationship with adaptability. Thus hypotheses $\mathrm{H} 2 \mathrm{~b}$ and $\mathrm{H} 2 \mathrm{c}$ are supported, however $\mathrm{H} 2 \mathrm{a}$ is not supported as there was no evidence that the use of a 'meansdriven' approach was correlated with the use of business cases at the portfolio level.

Finally, the analysis shows that portfolio monitoring intensity was negatively related the use of the adaptability practise and affordable loss principles, thus supporting the hypotheses $\mathrm{H} 3 \mathrm{~b}$ and $\mathrm{H} 3 \mathrm{c}$. Although we expected that the use of a 'means-driven' approach would be reduced by tight controls, the data did not support $\mathrm{H} 3 \mathrm{a}$.

\section{Discussion and conclusion}

The objective of this study was to explore the use of effectuation in decision making in project environments. By considering factors at both the project and portfolio level, we contribute new findings to whether and how effectuation logic has a role to play in project and portfolio management. As the traditional planning approach in project management is being challenged leading to calls for more flexible and adaptive approaches (Huff 2016), effectual decision making may enable the creation of opportunities while maintaining flexibility in uncertain environments. Combining literature from effectuation, project management and PPM, we developed and tested a framework that explores new ground by investigating effectuation from a project portfolio context as well as from the project-level in a multi-level empirical analysis.

Due to the importance of innovation and the strong support for managing innovative projects more flexibly, we considered the innovativeness of the project as a factor at the project level that could influence the degree of use of effectuation logic for decision making. At the portfolio level, we considered factors that affect project decision environments - in particular the use of business cases and the level of monitoring projects from a portfolio level. 
We based our hypotheses on the supposition that these portfolio level activities represent types of decision approaches that are largely characterized as causal and therefore may restrict the use of effectuation practices.

Our findings suggest that in projects with a low or medium level of innovativeness with relatively clear goals and pathways, causation-based logic is more likely than effectuation to dominate behaviour and decision making. When innovativeness is low, the finding support our inference that there would be a lower impetus to experiment and put 'affordable' losses at stake. In addition, although change also affects projects with low levels of innovativeness, the need to adapt to such changes is lower than in more innovative contexts. When causation logic is applied, such changes are less likely to be embraced as an opportunity, but instead are primarily seen as risks. With increasing innovativeness our findings on the whole support that effectual decision logic will be more likely to be used. Effectuation could be demonstrated in innovation projects in a number of ways, for example when exploring whether a technical solution may work or whether a technology can be used to create a product some additional tests or market research may be considered as an affordable loss, or when unexpected opportunities or unexpected threats occur effectuation may encourage consideration of opportunities to change the design or the technologies used.

These results are consistent with findings that effectuation is applied in R\&D projects with a high innovation degree (Küpper, 2010) and in small organizations' product innovation processes, where the approach can be described as resource-driven, stepwise, and open-ended (Berends et al., 2014). Our results suggest that, with innovative projects, the project managers oversee the evolution of projects as opportunities emerge and that the projects are designed to be flexible enough to be adjusted to changes in the environment. Uncertainty in highly innovative projects is also high, therefore estimating and limiting risks to affordable loss is more appropriate than predicting expected returns. Further, the affordable loss principle 
encourages innovative thinking as one can leverage "limited means in creative ways to generate new ends as well as new means" (Sarasvathy, 2008, p. 81). Our findings provide an important example of how a project-level characteristic (project innovativeness) relates to the use of effectuation as a decision logic.

These findings apply only to the effectuation principles affordable loss and adaptability. Our findings did not show any influence on the use of the effectuation principle 'meansdriven' stemming from the level of innovativeness, the use of business cases, or the intensity of monitoring. These findings align with the study by Brettel et al. (2012). They found performance effects from the use of the effectuation practices 'affordable loss' and 'adaptability' in highly innovative R\&D projects, but not from the 'means-driven' practices. One explanation for the finding that 'means-driven' practices may not influence the use of effectuation in project decision making could be that the available slack resources are not the most valuable ones, and therefore their usage is not advantageous. It is also possible that in a project portfolio context projects compete against each other for scarce resources to such a large extent that there are no slack resources available to apply a means-driven logic at the project level. Alternatively, it could be the case that when idle and valuable portfolio resources exist, decision makers are more likely to trigger a new project, with a new business plan, instead of opening up the possibility for existing projects to apply a 'means-driven practice'.

Although the factors we investigated did not influence the use of a 'means-driven' approach to decision making, there are arguments that suggest benefits from such an approach. For example, if organizations make extra resources available, particularly for innovative projects, project managers could be given more autonomy to make resource decisions and pursue new opportunities. 
The result that monitoring and business case control at the portfolio level affect the decision-making logic at the project-level is another important finding. By showing that such multi-level impacts exist, we justify further investigation into portfolio-level processes and how they may affect project-level processes. This is an area that has been paid little attention (Meiffort, 2015), but has the potential for strong impact due to the escalation in use of portfolio-level processes and organizational structures (such as the project management office). The findings support our hypotheses that monitoring and business case control are negatively related to the use of adaptability and affordable loss logics. This suggests that portfolio monitoring does constrain the actions taken by project managers. Monitoring and business case control tend to operate under the assumption that project goals and decision criteria are set - however in highly innovative situations, goals and criteria may adapt and evolve during the project as project teams and customers come to terms what is possible. Customers need to first learn what they "can want" before they are able to articulate what they want, and unexpected and potentially negative side-effects need to be considered as new options are evaluated. Thus, new assessment criteria may become important. Our findings show that the application of effectual reasoning in corporate settings plays a minor role in project environments. However for those who apply effectuation, the flexible and adaptive capabilities afforded by this approach are shown to support innovation - these are increasingly important capabilities that provide a new way of working to meet the challenges of delivering innovative outcomes in rapidly changing environments.

\subsection{Implications}

This study contributes to literature in several ways. First, we further enhance the rapidly growing body of knowledge about the use of effectuation as a decision logic and transfer it to a new field - the management of projects and project portfolios. We broaden the context of effectuation research beyond its origin in entrepreneurship and contribute to the 
generalizability of the theory. Second, this study reveals influences on the use of effectuation at both the project and the portfolio level. These findings contribute to the literature on project and portfolio management. Despite the rational and causation-based underpinnings of the project and portfolio management disciplines, our study has found that effectuation plays a role in project decision making, providing encouragement for further research in this area. If portfolio management is shown to be influential in the type of decision-making logic used at the project level, this has many implications. The decision to make use of governance control mechanisms has an effect that can permeate and influence project decision making. As effectuation has been shown to be an alternative decision logic to deal with highly innovative projects, organizations may consider introducing effectual thinking concepts to employees. Effectuation concepts could provide managers and decision makers with strategies to deal with uncertainty, improve flexibility and enable adaptation to change, and to improve creativity. Although it is early days for research in this area, our findings suggest that effectuation decision logic may provide an alternative perspective to assist decision makers meet challenges created by the need to produce innovative outcomes in an increasingly complex and dynamic environment.

\subsection{Limitations and future avenues of research}

A limitation of the study is the use of bipolar scales to measure effectuation and causation. Future research could explore effectuation and causation separately in order to examine the respondent's preference for either, or investigate consequences of hybrid decision-making logic. In addition, this study was limited to the exploration of the relationship of effectual principles with project innovativeness and portfolio governance. Other antecedents that support the application of effectual reasoning could be explored to deepen the understanding. Future research could also differentiate different types of portfolio control. While we applied a rather broad measure of monitoring intensity, other aspects such as strategic control 
(Kopmann et al., 2017) could also be included. This study has identified relationships between effectual decision making and innovative projects; future research should also consider the relationship between effectual decision making and success. In addition, other variables that may have an impact on the use of effectuation could be explored, such as leadership, motivation, autonomy, top management support, strategic values and orientation, entrepreneurial orientation, and risk-taking behaviour.

We have examined effectual decision making on the project level, thus the type of project manager plays an important role: their experience, personality and characteristics. Project managers with an entrepreneurial mindset might show more effectual behavior, or perhaps experienced project managers may be more likely to disregard the original project goals and exploit new opportunities as they emerge, however this remains unexplored. Additionally, the incentive for project managers to apply effectuation or causation logic is unknown. For example, if project leaders are incentivized for reaching project goals and following the business case, they may be more likely to make causal decisions. Even if they also considered options based on effectuation principles, they will likely discard them under these incentives. Thus, further research on the use of effectuation in project decision making could include exploration of the role and characteristics of the project manager.

We also see opportunities for research applying a longitudinal design which could explore whether effectuation and causation are applied in different stages of a project. This study uses cross-sectional data and cannot show the evolution of projects over time. Future research could explore whether the type of decision-making logic changes over the course of a project lifecycle.

\section{References}

Archer, N. ., and Ghasemzadeh, F. (1999). An integrated framework for project portfolio selection. International Journal of Project Management, 17(4), 207-216.

Artto, K., Martinsuo, M., Dietrich, P., and Kujala, J. (2008). Project strategy: strategy types 
and their contents in innovation projects. International Journal of Managing Projects in Business, 1(1), 49-70.

Atkinson, R. (1999). Project management: cost, time and quality, two best guesses and a phenomenon, its time to accept other success criteria. International Journal of Project Management, 17(6), 337-342.

Atkinson, H. (2006). Strategy implementation: a role for the balanced scorecard? Management Decision, 44(10), 1441-1460.

Berends, H., Jelinek, M., Reymen, I., and Stultiens, R. (2014). Product innovation processes in small firms: Combining entrepreneurial effectuation and managerial causation. Journal of Product Innovation Management, 31(3), 616-635.

Besner, C., and Hobbs, B. (2013). Contextualized project management practice: A cluster analysis of practices and best practices. Project Management Journal, 44(1), 17-34.

Blauth, M., Mauer, R., and Brettel, M. (2014). Fostering Creativity in New Product Development through Entrepreneurial Decision Making. Creativity and Innovation Management, 23(4), 495-509.

Blomquist, T., Hällgren, M., Nilsson, A., \& Söderholm, A. (2010). Project-as-practice: In search of project management research that matters. Project Management Journal, 41(1), 5-16.

Brettel, M., Mauer, R., Engelen, A., and Küpper, D. (2012). Corporate effectuation: Entrepreneurial action and its impact on R\&D project performance. Journal of Business Venturing, 27(2), 167-184.

Cai, L., Guo, R., Fei, Y., and Liu, Z. (2016). Effectuation, Exploratory Learning and New Venture Performance: Evidence from China. Journal of Small Business Management, 116.

Chandler, G. N., DeTienne, D. R., McKelvie, A., and Mumford, T. V. (2011). Causation and effectuation processes: A validation study. Journal of Business Venturing, 26(3), 375390.

Cicmil, S., Williams, T., Thomas, J., \& Hodgson, D. (2006). Rethinking Project Management: Researching the actuality of projects. International Journal of Project Management, 24(8), 675-686.

Clegg, S., Killen, C. P., Biesenthal, C., \& Sankaran, S. (2018). Practices, projects and portfolios: Current research trends and new directions. International Journal of Project Management, 36(2018), 762-772.

Conforto, E. C., and Amaral, D. C. (2010). Evaluating an agile method for planning and controlling innovative projects. Project Management Journal, 41(2), 73-80.

Conforto, E. C., Salum, F., Amaral, D. C., da Silva, S. L., and de Almeida, L. F. M. (2014). Can Agile Project Management Be Adopted by Industries Other than Software Development? Project Management Journal, 45(3), 21-34.

Cooke-Davies, T., Cicmil, S., Crawford, L., and Richardson, K. (2007). Mapping the strange landscape of complexity theory and its relationship. Project Management Journal, 38(2), $50-61$.

Cooper, R., Edgett, S. J., and Kleinschmidt, E. J. (2002). Portfolio Management: Fundamental for New Product Success. In The PDMA Toolbook for New Product Development (pp. 331-364).

Cooper, R., and Kleinschmidt, E. J. (1995). Performance typologies of new product projects. Industrial Marketing Management, 24(5), 439-456.

Donaldson, L. (2001) The contingency theory of organizations. Sage Publications, Thousand Oaks, CA.

Ekvall, G. (2008). Organizational climate for creativity and innovation. European Journal of Work and Organizatioal Psychology, 5(1), 105-123. 
Engwall, M. (2003). No project is an island: linking projects to history and context. Research Policy, 32(5), 789-808.

Gardiner, P. D., and Stewart, K. (2000). Revisiting the golden triangle of cost, time and quality: the role of NPV in project control, success and failure. International Journal of Project Management, 18(4), 251-256.

Gemünden, H.G., Lehner, P.; Kock, A. (2018). The project-oriented organization and its contribution to innovation. International Journal of Project Management, 36(1), 147160.

Hanisch, B., and Wald, A. (2012). A bibliometric view on the use of contingency theory in project management research. Project Management Journal, 43(3),4-23. Hennessey, B. A., and Amabile, T. M. (2009). Creativity. Annual Review of Psychology, 61(1), 569598.

Howell, D., Windahl, C., and Seidel, R. (2010). A project contingency frame- work based on uncertainty and its consequences. International Journal of Project Management, 28, 256-264.

Huff, A. S. (2016). Project Innovation: Evidence-Informed, Open, Effectual, and Subjective. Project Management Journal, 47(2), 8-25.

Jaafari, A. (2003). Project Management in the Age Complexity and Change. Project Management Journal, 34(3), 47-58.

Jensen, A., Thuesen, C., and Geraldi, J. 2016. The Projectification of Everything: Projects as a Human Condition. Project Management Journal, 47(3): 21-34.

Jerbrant, A., and Karrbom Gustavsson, T. (2013). Managing project portfolios: balancing flexibility and structure by improvising. International Journal of Managing Projects in Business, 6(1), 152-172.

Johansson, A., and McKelvie, A. (2012). Unpacking the antecedents of effectuation and causation in a corporate context. Frontiers of Entrepreneurship Research, 32(17), Article 1.

Jonas, D., Kock, A., and Gemünden, H. G. (2013). Predicting project portfolio success by measuring management quality - A longitudinal study. IEEE Transactions on Engineering Management, 60(2), 215-226.

Kamoche, K., and Cunha, M. P. (2001). Minimal structures: From jazz improvisation to product formation. Organization Studies, 22(5), 733-764.

Killen, C. P., \& Hunt, R. A. (2010). Dynamic capability through project portfolio management in service and manufacturing industries. International Journal of Managing Projects in Business, 3(1), 157-169.

Killen, C. P., Hunt, R. a., and Kleinschmidt, E. J. (2008). Project portfolio management for product innovation. International Journal of Quality and Reliability Management, 25(1), 24-38.

Killen, C. P., Jugdev, K., Drouin, N., and Petit, Y. (2012). Advancing project and portfolio management research: Applying strategic management theories. International Journal of Project Management, 30(5), 525-538.

Kock, A. (2007). Innovativeness and innovation success - A meta-analysis. Zeitschrift für Betriebswirtschaft, Special Issue 2007-2: 1-21.

Kock, A., and Gemünden, H. G. (2016). Antecedents to Decision-Making Quality and Agility in Innovation Portfolio Management. Journal of Product Innovation Management, 33(6), 670-686.

Kock, A., Gemünden, H. G., Salomo, S., and Schultz, C. (2011). The Mixed Blessings of Technological Innovativeness for the Commercial Success of New Products. Journal of Product Innovation Management, 28(s1), 28-43.

Kock, A., Heising, W., and Gemünden, H. G. (2015). How Ideation Portfolio Management Influences Front End Success. Journal of Product Innovation Management, 32(4), 539- 
555.

Kock, A., Heising, W., and Gemünden, H. G. (2016). A Contingency Approach on the Impact of Front-End Success on Project Portfolio Success. Project Management Journal.

Kopmann, J., Kock, A., Killen, C. P., and Gemunden, H. G. (2015). Business Case Control in Project Portfolios - An Empirical Investigation of Performance Consequences and Moderating Effects. Engineering Management, IEEE Transactions on, 62(4), 529-543.

Kopmann, J., Kock, A., Killen, C. P., and Gemunden, H. G. (2017): The role of project portfolio management in fostering both deliberate and emergent strategy. International Journal of Project Management, 35(4), 557-570.

Krebs, J. (2008). Agile portfolio management. Microsoft Press.

Lacerda, R. T. de O., Ensslin, L., and Ensslin, S. R. (2011). A performance measurement framework in portfolio management: A constructivist case. Management Decision, 49(4), 648-668.

Lechler, T. and Yang, S. (2017). Exploring the Role of Project Management in the Development of the Academic Agile Software Discourse: A Bibliometric Analysis. Project Management Journal, 48(1), 3-18.

Lenfle, Sylvain (2016). Floating in Space? On the Strangeness of Exploratory Projects. Project Management Journal 47(2), 47-61.

Leybourne, S. (2009). Improvisation and agile project management: a comparative consideration. International Journal of Managing Projects in Business, 2(4), 519-535.

Loch, C. (2000). Tailoring product development to strategy: case of a European technology manufacturer. European Management Journal, 18(3), 246-258.

March, J. G. (1991). Exploration and Exploitation in Organizational Learning. Organization Science, 2(1), 71-87.

Martinsuo, M. (2013). Project portfolio management in practice and in context. International Journal of Project Management, 31(6), 794-803.

Maylor, H., Vidgen, R., and Carver, S. (2008). Managerial complexity in project-based operations: A grounded model and its implications for practice. Project Management Journal, 39(S1), S15-S26.

McDermott, C. M., and O'Connor, G. C. (2002). Managing radical innovation: an overview of emergent strategy issues. Journal of Product Innovation Management, 19(6), 424438.

Meifort, A. K. (2016). Innovation portfolio management: A synthesis and research agenda. Creativity and Innovation Management, 25(2), 251-269.

Morrish, S. (2009). Portfolio entrepreneurs: an effectuation approach to multiple venture development. Journal of Research in Marketing and Entrepreneurship, 11(1), 32-48.

Müller, R. (2009). Project Governance: Fundamentals of project management. Gower Publishing, Ltd.

Müller, R., Martinsuo, M., and Blomquist, T. (2008). Project portfolio control and portfolio management performance in different contexts. Project Management Journal, 39(3), 2842.

Olsson, N. O. E. (2006). Management of flexibility in projects. International Journal of Project Management, 24(1), 66-74.

O'Reilly III, C. A., and Tushman, M. L. (2013). Organizational ambidexterity: Past, present, and future. Academy of Management Perspectives, 27(4): 324-338.

Perry, J. T., Chandler, G. N., and Markova, G. (2012). Entrepreneurial Effectuation: A Review and Suggestions for Future Research. Entrepreneurship Theory and Practice, 36(4), 837-861.

Read, S., Song, M., and Smit, W. (2009). A meta-analytic review of effectuation and venture performance. Journal of Business Venturing, 24(6), 573-587. 
Recker, J., Holten, R., Hummel, M., and Rosenkranz, C. (2017). How Agile Practices Impact Customer Responsiveness and Development Success: A Field Study. Project Management Journal, 48(2), 99-121.

Reymen, I. M. M. J., Andries, P., Berends, H., Mauer, R., Stephan, U., and Burg, E. (2015). Understanding dynamics of strategic decision making in venture creation: a process study of effectuation and causation. Strategic Entrepreneurship Journal, 9(4), 351-379.

Salomo, S., Weise, J., and Gemünden, H. G. (2007). NPD Planning Activities and Innovation Performance: The Mediating Role of Process Management and the Moderating Effect of Product Innovativeness. Journal of Product Innovation Management, 24(4), 285-302.

Sarasvathy, S. (2001). Causation and Effectuation: Toward a Theoretical Shift from Economic Inevitability to Entrepreneurial Contingency. The Academy of Management Review, 26(2), 243-263.

Sarasvathy, S. (2008). Effectuation: Elements of entreprenerial expertise. New York: Edward Elgar Publishing.

Sarasvathy, S., Kumar, K., York, J. G., and Bhagavatula, S. (2014). An Effectual Approach to International Entrepreneurship: Overlaps, Challenges, and Provocative Possibilities. Entrepreneurship Theory and Practice, 38(1), 71-93.

Serrador, P., and Turner, R. (2015). The relationship between project success and project efficiency. Project Management Journal, 46(1), 30-39.

Shenhar, A. J. (2001). One size does not fit all projects: exploring classical contingency domains. Management Science, 47(3): 394-414.

Shenhar, A. J., \& Dvir, D. (1996). Toward a typological theory of project management. Research Policy, 25(4), 607-632.

Stingl, V., and Geraldi, J. (2017). Errors, lies and misunderstandings: Systematic review on behavioural decision making in prjects. International Journal of Project Management 35 (2017) 121-135

Söderlund, J. (2011). Pluralism in Project Management: Navigating the Crossroads of Specialization and Fragmentation. International Journal of Management Reviews, 13(2), 153-176.

Svejvig, P., \& Andersen, P. (2015). Rethinking project management: A structured literature review with a critical look at the brave new world. International Journal of Project Management, 33(2), 278-290.

Teller, J., Kock, A., and Gemünden, H. G. (2014). Risk management in project portfolios is more than managing project risks: A contingency perspective on risk management. Project Management Journal, 45(4), 67-80.

Teller, J., Unger, B., Kock, A., and Gemünden, H. G. (2012). Formalization of project portfolio management: The moderating role of project portfolio complexity. International Journal of Project Management, 30(5), 596-607.

Turner, R. J., Anbari, F., and Bredillet, C. (2013). Perspectives on research in project management: the nine schools. Global Business Perspectives, 1(1), 3-28.

Viale, R. (1992). Cognitive Constraints of Economic Rationality. In Economics Bounded Rationality and Cognitive Revolution. Edward Elgar Publishing Limited, (pp. 174-193). Brookfield.

Wiltbank, R., Read, S., Dew, N., and Sarasvathy, S. (2009). Prediction and control under uncertainty: Outcomes in angel investing. Journal of Business Venturing, 24(2), 116133.

Wiltbank, R., and Sarasvathy, S. (2010). What effectuation is not: Further development of an alternative to rational choice. Academy of Management Meeting.

Winter, S. G. (2003). Understanding dynamic capabilities. Strategic Management Journal, 24(10), 991-995. 


\section{APPENDIX (Item wordings)}

Means-Driven Logic of the Project (2 items, alpha 0.73, project manager informant, bipolar scale from 1 [causation] to 7 [effectuation])

Desired goals have been the starting point for this project.
Available resources and capabilities have been the starting point for this project.

\section{The project specification was predominantly The project specification was predominantly based on given targets. based on given resources. \\ Concrete goals had a significant impact on the definition of the project. \\ Available resources and capabilities had a significant impact on the definition of the project.}

Affordable Loss Logic of the Project (2 items, alpha 0.60, project manager informant, bipolar scale from 1 [causation] to 7 [effectuation])

\begin{tabular}{ll}
\hline $\begin{array}{l}\text { We were careful to commit resources only if } \\
\text { sufficient profitability was warranted. }\end{array}$ & $\begin{array}{l}\text { We were careful not to commit more } \\
\text { resources than we could afford to lose. }\end{array}$ \\
\hline $\begin{array}{l}\text { The project budget was mainly approved } \\
\text { based on calculations of expected returns } \\
\text { (e.g., ROI). }\end{array}$ & $\begin{array}{l}\text { The project budget was mainly approved on } \\
\text { the basis of considerations about acceptable } \\
\text { losses. }\end{array}$ \\
$\begin{array}{l}\text { We evaluated the project's expected return } \\
\text { and profit. }\end{array}$ & $\begin{array}{l}\text { We evaluated the project regarding expected } \\
\text { risks and costs that we were willing to lose. }\end{array}$ \\
\hline
\end{tabular}

Adaptability Logic of the Project (4 items, alpha $=0.81$, project manager informant, bipolar scale from 1 [causation] to 7 [effectuation])

Please decide for each pair of statements on decision-making behaviour, which statement more likely applies to your project.

\begin{tabular}{ll}
\hline $\begin{array}{l}\text { We only integrated surprising results and } \\
\text { findings when the original project target was } \\
\text { at risk. }\end{array}$ & $\begin{array}{l}\text { We tried to integrate surprising results and } \\
\text { findings during the project - even though } \\
\text { this was not necessarily in line with the } \\
\text { original project target. }\end{array}$ \\
\hline $\begin{array}{l}\text { The project focused on reaching the project } \\
\text { target without any delay. }\end{array}$ & $\begin{array}{l}\text { The project was flexible enough to be } \\
\text { adjusted to new findings. }\end{array}$ \\
\hline $\begin{array}{l}\text { The project planning was carried out at the } \\
\text { beginning of the project. }\end{array}$ & $\begin{array}{l}\text { The project planning was carried out in } \\
\text { small steps during the project } \\
\text { implementation. }\end{array}$ \\
\hline $\begin{array}{l}\text { We primarily took care of reaching our } \\
\text { initially defined project targets without } \\
\text { delays. }\end{array}$ & $\begin{array}{l}\text { We allowed the project to evolve as } \\
\text { opportunities emerged - even though the } \\
\text { opportunities were not in line with the } \\
\text { original project target. }\end{array}$ \\
\hline
\end{tabular}


Innovativeness of the Project (5 items, alpha 0.85, project manager informant)

The novelty of the originally anticipated project results was very high compared to other projects.

The originally anticipated project results addressed new user / customer needs that we have not addressed before.

At the beginning of the project we did not yet have the necessary technical knowledge.

At the beginning of the project we had little practical experience in the application of the required technology.

In our project we could only partially rely on the existing technological competence of the company.

Business Case Application (3 items, Alpha 0.86, coordinator informant)

All projects must have a business case in order to enter the selection process.

„Must-Projects“ (mandatory projects) also have to prove a business case.

We intensively examine the business case within portfolio structuring.

Portfolio Monitoring Intensity (3 items, Alpha 0.79, coordinator informant)

We frequently examine our portfolio objectives (e.g., strategic alignment, net return, risk).

Within portfolio controlling, we analytically examine planned/actual performance deviations.

Within portfolio controlling, we systematically analyse all single projects. 